\title{
Longitudinal study of diet quality and change in asthma symptoms in adults, according to smoking status
}

\author{
Zhen $\mathrm{Li}^{1,2,3 *}$, Emmanuelle Kesse-Guyot ${ }^{4}$, Orianne Dumas ${ }^{1,2}$, Judith Garcia-Aymerich ${ }^{5,6,7}$,
} Bénédicte Leynaert $^{8,9}$, Christophe Pison ${ }^{10,11,12}$, Nicole Le Moual ${ }^{1,2}$, Isabelle Romieu ${ }^{13}$, Valérie Siroux ${ }^{14,15,16}$, Carlos A. Camargo $\mathrm{Jr}^{17}$, Rachel Nadif ${ }^{1,2}$ and Raphaëlle Varraso ${ }^{1,2}$

${ }^{1}$ Inserm, U1168, VIMA: Aging and Chronic Diseases, Epidemiological and Public Health Approaches, Villejuif F-94807, France

${ }^{2}$ Univ Versailles St-Quentin-en-Yvelines, UMR-S 1168, Montigny le Bretonneux F-78180, France

${ }^{3}$ Univ Paris-Sud, Orsay F-91400, France

${ }^{4}$ Université Paris 13, Equipe de Recherche en Epidémiologie Nutritionnelle (EREN), Centre de recherche en Epidémiologie et Statistiques Sorbonne Paris Cité, Inserm (U1153), Inra (U1125), Cnam, COMUE Sorbonne Paris Cité, Bobigny F-93000, France ${ }^{5}$ ISGlobal, Centre for Research in Environmental Epidemiology (CREAL), Barcelona E-08003, Spain

${ }^{6}$ Universitat Pompeu Fabra (UPF), Barcelona E-08002, Spain

${ }^{7}$ Consorcio de Investigación Biomédica en Red de Epidemiología y Salud Pública (CIBERESP), Barcelona E-08003, Spain

${ }^{8}$ Inserm, U1152, Physiopathologie et épidémiologie des maladies respiratoires, équipe Epidémiologie, Paris F-75018, France

${ }^{9}$ Univ Paris Diderot Paris-7, Paris F-75013, France

${ }^{10}$ Clinique Universitaire de Pneumologie, Pôle Thorax et Vaisseaux, Centre Hospitalier Universitaire (CHU) de Grenoble, Grenoble F-38043, France

${ }^{11}$ Inserm U1055, Grenoble F-38043, France

${ }^{12}$ Université Alpes Grenoble, Grenoble F-38400, France

${ }^{13}$ Instituto Nacional De Salud Publica, Cuernavac 62508, Mexico; currently at International Agency for Research on Cancer, Lyon F-69008, France

${ }^{14}$ Inserm, Institut Albert Bonniot (IAB), Team of Environmental Epidemiology Applied to Reproduction and Respiratory Health, Grenoble F-38042, France

${ }^{15}$ Université Grenoble Alpes, Institut Albert Bonniot (IAB), Team of Environmental Epidemiology Applied to Reproduction and Respiratory Health, Grenoble F-38042, France

${ }^{16}$ Centre Hospitalier Universitaire (CHU) de Grenoble, Institut Albert Bonniot (IAB), Team of Environmental Epidemiology Applied to Reproduction and Respiratory Health, Grenoble F-38042, France

${ }^{17}$ Department of Emergency Medicine, Massachusetts General Hospital, Harvard Medical School, Boston, MA 02114, USA

(Submitted 19 August 2016 - Final revision received 19 December 2016 - Accepted 31 January 2017)

\section{Abstract}

It has been hypothesised that increased asthma prevalence in westernised countries is associated with changes in lifestyle factors, including a poorer diet. However, little is known regarding the association between diet quality and asthma. In the diet-asthma association, the role of BMI as a potential mediator needs clarification; moreover, potential effect modification by non-diet sources of oxidants, such as smoking, merits investigation. We investigated the association between diet quality and change in asthma symptoms, as well as assessed effect modification by smoking, while accounting for BMI as a potential mediator. Using data from the French prospective Epidemiological study on the Genetics and Environment of Asthma study, we assessed diet quality using the Alternate Healthy Eating Index 2010 (AHEI-2010) at baseline and change in asthma symptoms (stable (reference), worsening, improved; mean follow-up time: 7 years). Mediation analysis was used to disentangle total and direct effects and the indirect effect mediated by BMI. The analyses included 969 adults (mean age 43 years; $49 \%$ men; $42 \%$ ever asthma). We observed a significant interaction between smoking and AHEI-2010 on change in asthma symptoms $\left(P_{\text {for interaction }}=0 \cdot 04\right)$. Among never smokers $(n$ 499), we observed a positive total effect (multivariable OR $1 \cdot 39 ; 95 \%$ CI $1 \cdot 07,1 \cdot 80)$ and a positive direct effect (OR 1.41; $95 \%$ CI 1.09, 1.80) of the AHEI-2010 (per ten-point increment) on improved symptoms. No indirect effect mediated through BMI was observed (OR 0.99; $95 \%$ CI 0.91, 1.07). Among former and current smokers, all effects were statistically non-significant. Better diet quality was associated with improved asthma symptoms over time in never smokers, independently of BMI.

Key words: Asthma: Diet scores: Smoking: BMI: Mediation analysis

Abbreviations: AHEI-2010, Alternate Healthy Eating Index 2010; EGEA, Epidemiological study on the Genetics and Environment of Asthma; SU.VI.MAX, SUpplémentation en VItamines et Minéraux AntioXydants.

* Corresponding author: Z. Li, fax +33 1455951 69, email zhen.li@inserm.fr 
The increased worldwide prevalence of asthma, particularly in westernised countries and countries transitioning to a western lifestyle, has suggested that this increase may result from changing environmental and behavioural factors ${ }^{(1)}$. In particular, modification in dietary habits (i.e. decreased intake of fruits/ vegetables and increased intake of 'westernised' ultra-processed foods) has led to a decreased intake of antioxidant vitamins and fatty acids and has been proposed as a plausible explanation for the increase in asthma prevalence ${ }^{(2)}$. On the basis of this prevailing hypothesis, most of the diet-asthma studies have focused on antioxidant or anti-inflammatory properties of dietary factors. However, taken together, these findings are inconclusive ${ }^{(3)}$, probably due to the complexity of both the exposure and the outcome, and consequently of their association.

Regarding diet assessment, studies on specific foods or nutrients have traditionally been conducted. Nevertheless, several conceptual and methodological limitations have been raised. A major concern is the fact that foods are consumed in the form of complex combinations (i.e. dishes and meals), which can interact with each other and influence their bioavailability and absorption. Therefore, studying the effects of diet quality, which can take into account correlations and interactions among foods and nutrients, has been proposed as an alternate approach ${ }^{(4)}$. Diet scores of diet quality, based on established knowledge on the role of dietary intakes in prevention of major chronic disease, may be of particular interest when investigating the role of diet in asthma among adults, for which no specific food or nutrient has clearly been identified. Summarising eleven diet components, the Alternate Healthy Eating Index 2010 (AHEI-2010) $^{(5)}$ is the latest evidence-based diet score reflecting the overall diet quality. Studying diet-asthma association using the AHEI-2010 diet score could provide some insight into the synergic effects of foods and nutrients on asthma.

Regarding asthma assessment, despite the wide use of incidence of doctor-diagnosed asthma as main outcome, there have been increasing concerns about its limitations. In particular, its dichotomous assumption of asthma fails to properly account for temporal phenotypic variability of the disease expression $^{(6)}$. Thus, the asthma symptom score - a multicategorical measure - has been proposed to study risk factors for asthma in longitudinal studies ${ }^{(7,8)}$. Applicable among individuals with and without asthma, the asthma symptom score either reflects asthma incidence or captures the temporal variability of the disease among individuals with asthma. The asthma symptom score, which has greater power in investigating risk factors ${ }^{(7,8)}$, may be particularly relevant to studies on dietary factors and asthma.

Two challenges manifest themselves when investigating the diet-asthma association. First, as obesity is a likely risk factor for asthma $^{(9)}$, and that better diet quality has been associated with a lower risk of obesity ${ }^{(10)}$, it is reasonable to posit that BMI is a potential mediator rather than a confounder in the diet-asthma association $^{(11)}$. The traditional analysing approach, in which $\mathrm{BMI}$ is adjusted for as a covariate, can over-adjust the association $^{(12)}$. To the best of our knowledge, no study has investigated the association between healthy diet and change in asthma symptoms, while addressing BMI as a mediator. Second, diet may interact with environmental and behavioural factors, some of which may be related to pulmonary oxidant/antioxidant balance and inflammation - two physiological processes involved in lung health ${ }^{(13)}$. Given that cigarette smoking, which is an important source of oxidants, has been associated with increased risk for adult-onset asthma ${ }^{(14)}$ and worse control of the disease ${ }^{(15)}$, addressing the potential modifying effect of smoking in the diet-asthma association is particularly relevant to clarifying the role of diet as a risk factor itself.

In the present longitudinal study, we aimed to investigate the association between diet quality estimated through the AHEI-2010 diet score and change in asthma symptoms considering BMI as a potential mediator, as well as to evaluate effect modification by smoking

\section{Methods}

\section{Study sample}

The Epidemiological study on the Genetics and Environment of Asthma (EGEA) study (EGEA, bronchial hyperresponsiveness and atopy) was initiated in 1991 and recruited 2047 participants from five cities in France (https://egeanet.vjf.inserm.fr/index. $\mathrm{php} / \mathrm{fr} /$ ), including asthma cases, their first-degree relatives and a group of controls. Protocol and descriptive characteristics of the EGEA study have been previously published ${ }^{(16,17)}$. Between 2003 and 2007, this population was contacted again for the second survey (EGEA2). Out of 2002 living participants, 1601 had a complete medical examination and completed a detailed respiratory questionnaire. Participants were also invited to complete a FFQ at EGEA2. Between 2011 and 2013, the third survey (EGEA3) - a follow-up study of EGEA2 - was performed using a self-administered questionnaire.

As diet was only measured at EGEA2, we used data collected at EGEA2 as baseline and EGEA3 as the follow-up. A total of 1601 subjects were recruited at EGEA2, and we applied several exclusion criteria in our analysis (online Supplementary Fig. S1). Participants were excluded at baseline on the basis of the following: (i) if they were < 16 years old ( $n 35$ ); (ii) did not fill in the FFQ ( $n$ 109), had an inadequate assessment of diet (i.e. blank item $\geq 4, n 60$ ) or had an implausibly high or low total energy intake ${ }^{(18)}$ (i.e. for men: $<800$ or $>17573 \mathrm{~kJ} / \mathrm{d}$ (>4200 kcal/d), for women: $<500$ or $>14644 \mathrm{~kJ} / \mathrm{d}$ (>3500 kcal/d); $n$ 161); (iii) had missing data for the asthma symptom score at EGEA2 ( $n$ 10); or (iv) had missing data for smoking status (n 2). The final baseline population included 1224 participants. During follow-up, twenty-five participants died, twenty-one changed their address, 117 did not respond at EGEA3 and twenty-two refused to participate at EGEA3. A total of 1039 participants responded to the EGEA3 questionnaire. Compared with respondents at EGEA3 ( $n$ 1039), participants lost to followup ( $n$ 185) were more likely to be men $(P<0.001)$, had lower AHEI-2010 scores (mean score: $50 v$. 52, respectively; $P=0.03$ ), and had similar age, BMI, educational level, physical activity and asthma status $(P>0.05)$ (online Supplementary Table S1). After further excluding seventy participants with missing data for the asthma symptom score assessed at EGEA3, the final study sample included 969 participants. 
Compared with included participants ( $n$ 969), excluded adults ( $n$ 597) had similar age, BMI, physical activity, sex, smoking status and asthma status $(P>0.05)$, but they less often had higher education levels ( $43 v .51 \%$, respectively; $P=0.002$ ) (online Supplementary Table S2).

This study was conducted according to the guidelines laid down in the Declaration of Helsinki, and all procedures involving human subjects/patients were approved by the relevant institutional review board committees (Cochin Port-Royal Hospital and Necker-Enfants Malades Hospital, Paris). Written informed consent was obtained from all subjects/patients.

\section{Dietary intakes}

At EGEA2, a 118-item, semi-quantitative FFQ based on a French, validated dietary questionnaire ${ }^{(19)}$ was used to assess average dietary intakes during the previous 12 months. For each food item, participants indicated their frequency of consumption (eight categories) ranging from 'never or $<1$ time/month' to ' $\geq 4$ times/d' for a standard portion size. We converted the frequency of consumption for each item to average daily intakes (serving/d or $\mathrm{g} / \mathrm{d}$ ). By using the French food composition table from the SUpplémentation en VItamines et Minéraux AntioXydants (SU.VI.MAX) study ${ }^{(20)}$, we calculated nutrient intakes and total energy intake $(\mathrm{kJ} / \mathrm{d}(\mathrm{kcal} / \mathrm{d}))$.

Scoring criteria of the AHEI-2010 have been described in detail elsewhere ${ }^{(5)}$. In brief, the AHEI-2010 score includes eleven components. A high AHEI-2010 score denotes high intake of vegetables, fruits, whole grains, nuts and legumes, long-chain $n-3$ fatty acids and PUFA; moderate intake of alcohol; and low intake of sugar-sweetened drinks and fruit juice, red/processed meat, trans-fat and $\mathrm{Na}$. For each component, a score from 0 to 10 was allocated based on its intake, and intermediate values were scored proportionally. The total AHEI-2010 score sums scores of all the eleven components, and ranges from 0 to 110; a higher score represents a healthier diet. In the EGEA study, we calculated a modified AHEI-2010 including all the items except for trans-fat, which is not available in the French food composition table from the SU.VI.MAX study; intake of whole grains was estimated though intake of cereal fibre. Foods and nutrients included in the scoring of each component of the AHEI-2010 are presented in the online Supplementary Table S3. Therefore, the highest value for the AHEI-2010 diet score in the EGEA study was 100 (rather than 110). The AHEI-2010 diet score was used as a continuous variable in the analysis.

\section{Change in asthma symptoms}

The asthma symptom score has been validated as a continuous measure, which is applicable in individuals with and without asthma, to study risk factors for asthma in longitudinal studies. Compared with dichotomous definitions of asthma, increased power in identifying risk factors was suggested when using the asthma symptoms score ${ }^{(7,8)}$. The asthma symptom score was calculated at both EGEA2 and EGEA3. Ranging from 0 to 5, the score is based on the number of respiratory symptoms occurring during the past 12 months reported in the questionnaire: (i) breathless while wheezing, (ii) woken up with chest tightness, (iii) attack of shortness of breath at rest, (iv) attack of shortness of breath after exercise and (v) woken by attack of shortness of breath. Change in asthma symptom score for each individual was categorised as 'stable' if EGEA3 score-EGEA2 score $=0$, 'worsening' if EGEA3 score-EGEA2 score $>0$ and 'improved' if EGEA3 score-EGEA2 score $<0$.

\section{Other variables}

Weight and height of the participants were measured at EGEA2 by trained health technicians. Body weight was measured in kilograms; height was measured to the nearest centimetre using a stadiometer. BMI $\left(\mathrm{kg} / \mathrm{m}^{2}\right)$ was calculated as weight $/$ height $^{2}$, and was used as a continuous variable in the analysis. Age, sex, smoking status (never and former and current smoking), educational level (university degree or equivalent) and physical activity were assessed at baseline (EGEA2). Leisure-time physical activity was assessed in metabolic equivalent (MET) per week, taking into account a variety of intensive activities (such as jogging, aerobic, swimming, cycling, tennis, soccer, digging in the garden), moderate activities (such as cleaning, walking, golf, slight gardening) and light activities (such as reading, watching TV, office work, driving, eating). Average physical activity was estimated by summing the product of average activating active time per week and the MET value of each activity.

To take into account the case-control design of the EGEA study, we also defined asthma status at EGEA2 (ever asthma or never asthma). Ever asthma was defined by being recruited as an asthma case in chest clinics at EGEA1 or responding positively to at least one of the two questions at EGEA1 or EGEA2: (1) 'Have you ever had attacks of breathlessness at rest with wheezing?' and (2) 'Have you ever had asthma attacks?'. Never asthma was defined by absence of asthma at EGEA1 and EGEA2.

\section{Statistical analysis}

As smoking may modify the association between overall diet quality and change in asthma symptoms, we formally tested the interaction between smoking habits and AHEI-2010 score. As the interaction was significant $\left(P_{\text {for interaction }}=0.04\right)$, analyses were conducted separately among never, former and current smokers.

In the association between overall diet quality and change in asthma symptom score during follow-up (stable, worsening or improved), BMI at baseline was considered as a potential mediator, and age, sex, educational level, leisure-time physical activity, total daily energy intake and asthma status at baseline were considered as potential confounders (Fig. 1). To disentangle the direct effect and the indirect effect mediated by BMI, we applied a mediation analysis in the counterfactual framework $^{(21,22)}$. In brief, using a marginal structural model, the mediation analysis was implemented by the following steps: (i) we created a new data set by repeating each observation ten times ${ }^{(21)}$ including a new variable $A^{*}$, which was each time set to randomly drawn values from a normal distribution with the mean and standard deviation matching the observed AHEI-2010 score (denoted by $A$ ); (ii) a generalised linear regression model was applied to the new data set to estimate the association between BMI and AHEI-2010 score, first 
Fig. 1. Conceptual model of the association between Alternate Healthy Eating Index 2010 (AHEl-2010) and change in asthma symptoms taking into account BMI as a potential mediator. EGEA, Epidemiological study on the Genetics and Environment of Asthma.

using the original variable $A$ and then the new variable $A^{*}$; (iii) using predicted probabilities from the models with $A$ and $A^{*}$, the individual, stabilised weights were calculated as $\quad W_{i}^{c}=P\left(M=M_{i} \mid A=A_{i}^{*}, C=C_{i}\right) / P\left(M=M_{i} \mid A=A_{i}, C=C_{i}\right)$, where $C$ denoted all the confounders; and (iv) a weighted, multinomial logistic regression model was applied to simultaneously estimate the association between AHEI-2010 ( $A$ and $A^{*}$ ) and change in asthma symptom score.

To evaluate how much of the total effect was due to the effect of BMI, we calculated the 'proportion explained' by BMI as $\left(O R_{\mathrm{TE}}-O R_{\mathrm{DE}}\right) /\left(O R_{\mathrm{TE}}-1\right)^{(22)}$, where $O R_{\mathrm{TE}}$ and $O R_{\mathrm{DE}}$ were, respectively, the OR of total effect and direct effect. The total, direct and indirect effects were presented as OR comparing with the stable score group per ten points increment in the AHEI-2010 score. 95\% CI were estimated using 1000 bootstrap samples.

Interactions between AHEI-2010 and BMI were tested by adding the product term of $A \times A^{*}$ in the model. As no interaction was observed between AHEI-2010 diet score and BMI, the exposure-mediator interaction term was not included in our mediation model $\left(P_{\text {for interaction }}=0.70,0.94\right.$ and 0.73 among never, former and current smokers, respectively).

We assumed that the following conditions were satisfied for the application of mediation analysis ${ }^{(21)}$ : no unmeasured confounders for the associations between (i) AHEI-2010 and asthma score, (ii) BMI and asthma score, (iii) AHEI-2010 and BMI; and (iv) no BMI-asthma score confounders affected by the AHEI-2010.

As women have a healthier diet than men ${ }^{(23)}$, we conducted analyses stratified based on sex. Considering the case-control design of the EGEA study, we also performed a stratified analysis on asthma status at EGEA2. Participants with high daily total energy intake are more likely to be overweight or obese in case of inadequate physical activity, but they could have a relatively high AHEI-2010 score because of high intakes of healthy foods. Thus, we further evaluated whether the association was modified by total energy intake (low $(<9966 \mathrm{~kJ} / \mathrm{d}(<2382 \mathrm{kcal} / \mathrm{d})$, median value) $v$. high $(\geq 9966 \mathrm{~kJ} / \mathrm{d}(\geq 2382 \mathrm{kcal} / \mathrm{d}))$ energy intake). Besides, to minimise the possible overlap between asthma and chronic obstructive pulmonary disease (COPD), we conducted a sensitivity analysis excluding participants who had a ratio of post-bronchodilator forced expiratory volume in $1 \mathrm{~s}$ to forced vital capacity $\left(\mathrm{FEV}_{1}: \mathrm{FVC}\right)<70 \%{ }^{(24)}$. All analyses were performed using SAS version 9.3 (SAS Institute Inc.).

\section{Results}

\section{Characteristics of the population}

Among 969 participants included in this analysis, 49\% were men and $42 \%$ had ever asthma at baseline (EGEA2) (Table 1). The mean age was 43 years; $51 \%$ of the participants were never smokers, $27 \%$ former smokers and $22 \%$ current smokers. The AHEI-2010 diet score varied from 23.5 to 80.9 , with a mean score of 51.6 (online Supplementary Fig. S2). The mean AHEI-2010 score was higher among former smokers than never and current smokers (online Supplementary Fig. S3 and S4). Roughly half of the participants (47\%) reported no asthma symptoms at baseline, $23 \%$ reported one asthma symptom and $30 \%$ reported more than one asthma symptom (Table 1 ).

Compared with never smokers, former smokers were older, more likely to be men, overweight or obese and had higher scores (healthier intakes) for intakes of sweetened drinks and for alcohol. Current smokers also differed from never smokers in that they were younger, more likely to be men, less likely to be overweight or obese, had a higher score for alcohol intake and had lower scores (less healthy intake) for fruit as well as for $\mathrm{red} /$ processed meat intakes.

\section{Association between overall diet quality and change in asthma symptom score}

The mean follow-up time for the participants was 7 years (varies from 5 to 9 years). Among never smokers, 54\% of the participants had a stable symptom score between EGEA2 and EGEA3, 19\% had worsening symptom score and $27 \%$ had improved symptom score; the mean AHEI-2010 diet scores were 50.7, 49.2 and 51.9, respectively. The AHEI-2010 was negatively associated with BMI (adjusted $\beta$ : $-0 \cdot 05 ; 95 \% \mathrm{CI}$ $-0.09,-0 \cdot 01 ; P=0.03)$. The means of BMI were $24 \cdot 1,24.2$ and $25.6 \mathrm{~kg} / \mathrm{m}^{2}$ among participants who had stable, improved and worsening symptoms, respectively. Per $1 \mathrm{~kg} / \mathrm{m}^{2}$ increment in BMI, the adjusted OR were 1.02 (95\% CI 0.96, 1.07) when comparing the improved group with the stable group and 1.08 (95\% CI 1.02, 1.14) when comparing the worsening group with the stable group.

Using mediation analysis, the OR for the total effect was 1.39 (95\% CI 1.07,1-80) per ten points increment in the AHEI-2010 score comparing the improved group with the stable group, after adjustment for age, sex, educational level, physical activity, 
Table 1. Baseline characteristics of participants according to smoking status ( $n$ 969) (Numbers and percentages; mean values and standard deviations)

\begin{tabular}{|c|c|c|c|c|c|c|c|c|c|}
\hline & \multicolumn{2}{|c|}{ All $(n$ 969) } & \multicolumn{2}{|c|}{ Never smokers $(n$ 499) } & \multicolumn{2}{|c|}{ Former smokers ( $n$ 259) } & \multicolumn{2}{|c|}{ Current smokers ( $n$ 211) } & \multirow[b]{2}{*}{$P^{\star}$} \\
\hline & $n$ & $\%$ & $n$ & $\%$ & $n$ & $\%$ & $n$ & $\%$ & \\
\hline Men & 475 & 49 & 219 & 44 & 142 & 55 & 114 & 54 & 0.004 \\
\hline BMI $\left(\mathrm{kg} / \mathrm{m}^{2}\right)$ & & & & & & & & & $<0.001$ \\
\hline$<20$ & 93 & 10 & 42 & 9 & 17 & 7 & 34 & 17 & \\
\hline $20-24.9$ & 490 & 53 & 269 & 56 & 107 & 44 & 114 & 56 & \\
\hline $25-29 \cdot 9$ & 253 & 27 & 122 & 25 & 88 & 36 & 43 & 21 & \\
\hline$\geq 30$ & 90 & 10 & 47 & 10 & 31 & 13 & 12 & 6 & \\
\hline Higher education & 493 & 51 & 256 & 51 & 128 & 49 & 109 & 52 & 0.84 \\
\hline Ever asthma at EGEA2 & 408 & 42 & 216 & 43 & 99 & 38 & 93 & 44 & 0.33 \\
\hline Asthma symptom score at EGEA2 & & & & & & & & & 0.12 \\
\hline 0 & 458 & 47 & 245 & 49 & 129 & 50 & 84 & 40 & \\
\hline 1 & 225 & 23 & 114 & 23 & 60 & 23 & 51 & 24 & \\
\hline \multirow[t]{2}{*}{$2-5$} & 286 & 30 & 140 & 28 & 70 & 27 & 76 & 36 & \\
\hline & Mean & SD & Mean & SD & Mean & SD & Mean & SD & \\
\hline Age (years) & 43 & 16 & 42 & 16 & 50 & 14 & 35 & 14 & $<0.001$ \\
\hline $\mathrm{BMI}\left(\mathrm{kg} / \mathrm{m}^{2}\right)$ & 24.4 & 4.2 & 24.4 & 4.3 & $25 \cdot 2$ & 4 & 23.4 & 3.8 & $<0.001$ \\
\hline Total energy intake $(\mathrm{kJ} / \mathrm{d})$ & 10150 & 2690 & 10200 & 2669 & 9895 & 2544 & 10359 & 2895 & 0.15 \\
\hline Total energy intake $(\mathrm{kcal} / \mathrm{d})$ & 2426 & 643 & 2438 & 638 & 2365 & 608 & 2476 & 692 & 0.15 \\
\hline Leisure-time physical activity (MET/week) & 45 & 17 & 45 & 17 & 45 & 16 & 44 & 17 & 0.44 \\
\hline AHEI-2010 diet score & 51.6 & 9.3 & $50 \cdot 8$ & $9 \cdot 4$ & 53.9 & 9.2 & 51.0 & $9 \cdot 0$ & $<0.001$ \\
\hline \multicolumn{10}{|l|}{ Component score of AHEI-2010 } \\
\hline Vegetables & 6.9 & 2.6 & 7.0 & 2.5 & 7.1 & 2.6 & 6.6 & $2 \cdot 7$ & 0.14 \\
\hline Fruits & $6 \cdot 8$ & 3.1 & 6.9 & 3.1 & $7 \cdot 1$ & $2 \cdot 9$ & 6.1 & $3 \cdot 3$ & 0.001 \\
\hline Whole grains & 4.5 & 1.9 & 4.6 & 2.0 & $4 \cdot 1$ & 1.7 & 4.8 & 1.9 & $<0.001$ \\
\hline Sugar-sweetened drinks and fruit juice & 4.6 & $4 \cdot 2$ & 4.4 & 4.2 & $5 \cdot 4$ & 4.1 & $4 \cdot 3$ & 4.0 & 0.004 \\
\hline Nuts and legumes & 1.5 & $2 \cdot 1$ & 1.4 & 1.9 & $1 \cdot 7$ & $2 \cdot 3$ & 1.6 & $2 \cdot 0$ & 0.26 \\
\hline Red and processed meat & 3.0 & $2 \cdot 6$ & $3 \cdot 1$ & 2.6 & $3 \cdot 2$ & 2.6 & $2 \cdot 4$ & $2 \cdot 4$ & 0.002 \\
\hline Long-chain $n-3$ fatty acids & $9 \cdot 2$ & $2 \cdot 0$ & $9 \cdot 2$ & $2 \cdot 1$ & $9 \cdot 3$ & 1.9 & $9 \cdot 2$ & $2 \cdot 0$ & 0.56 \\
\hline PUFA & 4.0 & 1.7 & 3.9 & 1.7 & 4.0 & 1.6 & $4 \cdot 2$ & 1.6 & 0.18 \\
\hline $\mathrm{Na}$ & $5 \cdot 1$ & 3.2 & $5 \cdot 1$ & 3.2 & 5.5 & 3.2 & 4.9 & 3.3 & 0.17 \\
\hline Alcohol & 6.0 & 3.9 & 5.3 & 3.9 & $6 \cdot 6$ & 3.7 & 6.9 & 3.6 & $<0.001$ \\
\hline
\end{tabular}

EGEA, Epidemiological study on the Genetics and Environment of Asthma; MET, metabolic equivalent; AHEI-2010, Alternate Healthy Eating Index 2010.

* Overall $P$ values were calculated from ANOVA for continuous variables (e.g. age) and from Pearson's $\chi^{2}$ test for categorised variables (e.g. sex) among the never, former and current smokers. 
total energy intake and asthma status (Fig. 2). The OR was 1.41 (95\% CI 1.09, 1.80) for the direct effect, and no indirect effect mediated through BMI was observed (0.99 (95\% CI: 0.91, 1.07), accounted for $5 \%$ of the total effect). No association was observed between AHEI-2010 scores and worsening asthma symptoms.

Among former smokers and current smokers, we observed no association between the AHEI-2010 diet score and the change in asthma symptom score (Table 2).

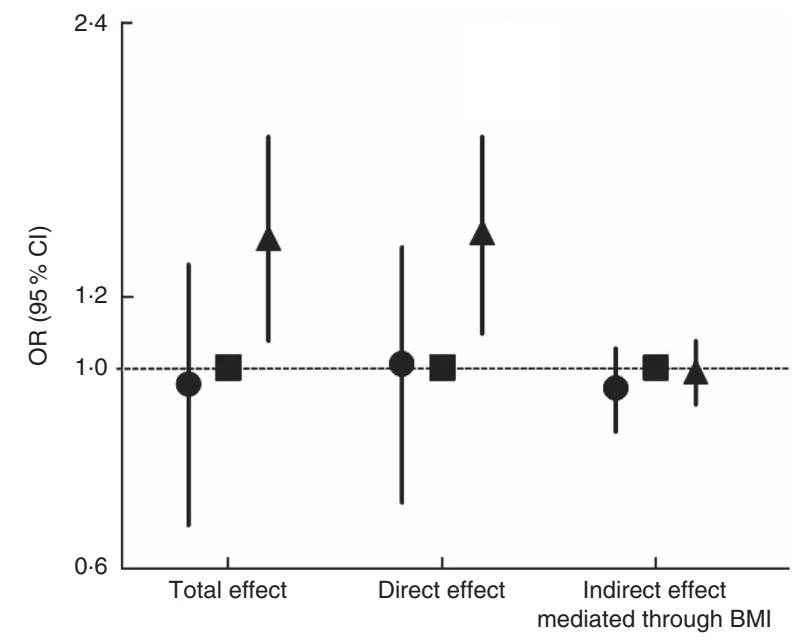

Fig. 2. Association between Alternate Healthy Eating Index 2010 (AHEI-2010) diet score and change in asthma symptoms among never smokers. A mediation analysis in the counterfactual framework was applied to estimate the total, direct effects and the indirect effect mediated through BMI, after adjustment for age, sex, educational level, leisure-time physical activity, total daily energy intake and asthma status. OR and $95 \% \mathrm{Cl}$ were estimated for each increment of ten points in the AHEI-2010 diet score using 1000 bootstrapped samples. - W Worsening ( $n$ 93); $\longrightarrow$, stable ( $n$ 269) (reference); $\longrightarrow$, improved ( $n$ 137).

\section{Sensitivity analysis}

As the association was observed among never smokers only, we performed several sensitivity analyses in this subgroup of participants. Several stratified analyses (according to sex, asthma status at baseline and total energy intake) showed similar results, although the statistical power was limited (Table 3). The analysis excluding participants who had a ratio of $\mathrm{FEV}_{1}: \mathrm{FVC}<70 \%$ ( $n$ 47) yielded similar results: comparing the improved group ( $n$ 123) with the stable group ( $n$ 375), the adjusted OR was 1.47 (95\% CI 1.07, 1.98) for the total effect, 1.47 (95\% CI 1.08, 1.96) for the direct effect and 0.99 (95\% CI $0 \cdot 90,1.07)$ for the indirect effect mediated through BMI.

Modelling change in the asthma symptom score as a continuous variable also showed a consistent association between AHEI-2010 diet score and improvement in asthma symptoms among never smokers only: the adjusted $\beta$ was 0.13 (95\% CI $0.01,0.25)$ for the total effect, $0.12(95 \%$ CI $0.01,0.24)$ for the direct effect and $0.01(95 \% \mathrm{CI}-0.03,0 \cdot 05)$ for the indirect effect mediated through BMI.

\section{Discussion}

In this prospective study with a 7-year follow-up period, we report a significant association between high diet quality (measured by the AHEI-2010 diet score) and improvement in asthma symptoms over time among never smokers only. Smoking habit appeared to be an effect modifier in the healthy diet-asthma association. Further, using mediation analysis in the counterfactual framework, BMI was unlikely a mediator in this association.

Assessment of overall diet either through dietary patterns or diet scores is the best available tool to take into account correlations and interactions among foods and nutrients ${ }^{(4)}$. Although dietary patterns are derived using data-driven statistical methods and vary according to studies, diet scores are developed

Table 2. Associations between Alternate Healthy Eating Index 2010 (AHEl-2010) diet score and change in asthma symptoms according to smoking status*

(Odds ratios and $95 \%$ confidence intervals)

\begin{tabular}{|c|c|c|c|c|c|c|}
\hline & \multicolumn{2}{|r|}{ Stable } & \multicolumn{2}{|c|}{ Worsening } & \multicolumn{2}{|c|}{ Improved } \\
\hline & OR & $95 \% \mathrm{Cl}$ & OR & $95 \% \mathrm{Cl}$ & OR & $95 \% \mathrm{Cl}$ \\
\hline \multicolumn{7}{|c|}{ Never smokers ( $n$ 499) } \\
\hline$n$ & \multicolumn{2}{|r|}{269} & \multicolumn{2}{|c|}{93} & \multicolumn{2}{|c|}{137} \\
\hline Total effect & & Ref. & 0.96 & $0.67,1.30$ & 1.39 & $1.07,1.80$ \\
\hline Direct effect & & Ref. & 1.01 & $0.71,1.36$ & 1.41 & $1.09,1.80$ \\
\hline Indirect effect & & Ref. & 0.95 & $0.85,1.05$ & 0.99 & $0.91,1.07$ \\
\hline \multicolumn{7}{|c|}{ Former smokers ( $n$ 259) } \\
\hline$n$ & & 140 & \multicolumn{2}{|c|}{52} & \multicolumn{2}{|c|}{67} \\
\hline Total effect & & Ref. & 0.72 & $0.43,1.09$ & 0.84 & $0.53,1.23$ \\
\hline Direct effect & & Ref. & 0.77 & $0.47,1.16$ & 0.86 & $0.55,1.28$ \\
\hline Indirect effect & & Ref. & 0.94 & $0.80,1.08$ & 0.98 & $0.85,1 \cdot 10$ \\
\hline \multicolumn{7}{|c|}{ Current smokers ( $n$ 211) } \\
\hline$n$ & & 103 & \multicolumn{2}{|c|}{46} & \multicolumn{2}{|c|}{62} \\
\hline Total effect & & Ref. & 1.54 & $0.79,2.78$ & 1.08 & $0.67,1.67$ \\
\hline Direct effect & & Ref. & 1.54 & $0.81,2.79$ & 1.07 & $0.65,1.62$ \\
\hline Indirect effect & & Ref. & 1.00 & $0.87,1.14$ & 1.01 & $0.89,1.16$ \\
\hline
\end{tabular}


Table 3. Associations between Alternate Healthy Eating Index 2010 (AHEl-2010) score and change in asthma symptoms in subgroups according to sex, asthma status and total energy intake among never smokers* (Odds ratios and $95 \%$ confidence intervals)

\begin{tabular}{|c|c|c|c|c|c|c|}
\hline & \multicolumn{2}{|r|}{ Stable } & \multicolumn{2}{|c|}{ Worsening } & \multicolumn{2}{|c|}{ Improved } \\
\hline & OR & $95 \% \mathrm{Cl}$ & OR & $95 \% \mathrm{Cl}$ & OR & $95 \% \mathrm{Cl}$ \\
\hline \multicolumn{7}{|l|}{ Stratified on sex } \\
\hline \multicolumn{7}{|l|}{ Men $(n 219)$} \\
\hline$n$ & & 125 & \multicolumn{2}{|c|}{34} & \multicolumn{2}{|c|}{60} \\
\hline Total effect & & Ref. & 1.09 & $0.57,1.84$ & 1.41 & $0.85,2 \cdot 20$ \\
\hline Direct effect & & Ref. & $1 \cdot 13$ & $0.58,1.97$ & 1.41 & $0.86,2.19$ \\
\hline Indirect effect & & Ref. & 0.97 & $0.81,1.13$ & 1.00 & $0.87,1.13$ \\
\hline \multicolumn{7}{|l|}{ Women $(n 280)$} \\
\hline$n$ & & 144 & \multicolumn{2}{|c|}{59} & \multicolumn{2}{|c|}{77} \\
\hline Total effect & & Ref. & 0.97 & $0.60,1.40$ & 1.41 & $0.98,2.07$ \\
\hline Direct effect & & Ref. & 1.03 & $0.66,1.45$ & 1.44 & $1.01,2.06$ \\
\hline Indirect effect & & Ref. & 0.94 & $0.82,1.09$ & 0.98 & $0.87,1.10$ \\
\hline \multicolumn{7}{|c|}{ Stratified on asthma status } \\
\hline \multicolumn{7}{|c|}{ Never asthma ( $n$ 283) } \\
\hline$n$ & & 185 & \multicolumn{2}{|c|}{43} & \multicolumn{2}{|c|}{55} \\
\hline Total effect & & Ref. & $1 \cdot 12$ & $0.66,1.78$ & 1.41 & $0.94,2 \cdot 10$ \\
\hline Direct effect & & Ref. & $1 \cdot 16$ & $0.71,1.80$ & 1.42 & $0.95,2.06$ \\
\hline Indirect effect & & Ref. & 0.96 & $0.82,1.11$ & 0.99 & $0.88,1.11$ \\
\hline \multicolumn{7}{|c|}{ Ever asthma ( $n$ 216) } \\
\hline$n$ & & 84 & \multicolumn{2}{|c|}{50} & \multicolumn{2}{|c|}{82} \\
\hline Total effect & & Ref. & 0.87 & $0.52,1.33$ & 1.42 & $0.88,2.23$ \\
\hline Direct effect & & Ref. & 0.92 & $0.54,1.43$ & 1.41 & $0.87,2.25$ \\
\hline Indirect effect & & Ref. & 0.95 & $0.81,1.12$ & 1.01 & $0.88,1.14$ \\
\hline Stratified on total er & ke† & & & & & \\
\hline High total energy & 250) & & & & \multirow{2}{*}{\multicolumn{2}{|c|}{70}} \\
\hline$n$ & & 130 & \multicolumn{2}{|c|}{50} & & \\
\hline Total effect & & Ref. & 1.07 & $0.65,1.61$ & 1.49 & $0.97,2.33$ \\
\hline Direct effect & & Ref. & $1 \cdot 11$ & $0.70,1.65$ & 1.49 & $0.98,2.25$ \\
\hline Indirect effect & & Ref. & 0.96 & $0.82,1.11$ & 1.00 & $0.89,1.12$ \\
\hline \multicolumn{7}{|c|}{ Low total energy intake ( $n$ 249) } \\
\hline$n$ & & 139 & \multicolumn{2}{|c|}{43} & \multicolumn{2}{|c|}{67} \\
\hline Total effect & & Ref. & 0.86 & $0.48,1.41$ & 1.29 & $0.84,1.93$ \\
\hline Direct effect & & Ref. & 0.90 & $0.53,1.44$ & 1.32 & $0.85,1.92$ \\
\hline Indirect effect & & Ref. & 0.95 & $0.76,1.12$ & 0.98 & $0.86,1.11$ \\
\hline
\end{tabular}

on the basis of established knowledge on nutrition, and thus provide a common tool to evaluate the potential effect of overall diet quality in different populations ${ }^{(4)}$.To date, a few studies have looked into the association between diet quality and asthmarelated outcomes in adults. According to a case-control study in Portugal, higher adherence to the 'alternate Mediterranean Diet' (high intakes of vegetables, legumes, fresh fruits, nuts, whole grains, fish, ethanol, ratio of monounsaturated:saturated fat and low red:processed meat intake) was associated with better asthma control $^{(25)}$. A randomised controlled trial (RCT) conducted in New Zealand reported no improvement in asthma control over 12 weeks for the interventional groups encouraged to adopt a Mediterranean diet, but perhaps due to the small sample size ( $n$ 38) and the short follow-up time ${ }^{(26)}$. Recently, a pilot RCT performed in the USA ${ }^{(27)}$ reported that adults with persistent asthma had better asthma control after a 6-month healthy eating intervention based on the Dietary Approaches to Stop Hypertension score summing nine nutrients (including total fat, saturated fat, protein, cholesterol, fibre, $\mathrm{Mg}, \mathrm{Ca}, \mathrm{Na}$ and $\mathrm{K}$ ). Regarding incidence of asthma, one US study reported no association between AHEI-2010 and adult-onset asthma in men and women ${ }^{(28)}$.
Rather than an aetiological risk factor for incidence of asthma, investigators have proposed that dietary factors are more likely to be a disease modifier among adults ${ }^{(29)}$. Under this circumstance, the asthma symptom score might be a more proper and powerful tool for investigating the association between diet scores and asthma. On the basis of five symptoms specific to asthma, the change in asthma symptom score predicts asthma incidence and activity among participants without asthma ${ }^{(7,8)}$, and captures relapse or exacerbation of the disease among participants with asthma. Recently, using the asthma symptom score, we reported a positive association between high cured-meat intake and worsening asthma symptoms ${ }^{(30)}$, although two studies in the USA previously reported no association between cured-meat intake and asthma when using the dichotomous definition of asthma incidence $^{(31,32)}$. As our study sample included $42 \%$ participants with ever asthma, we performed a stratified analysis according to asthma status at EGEA2. Results of similar magnitude were obtained in participants with and without asthma at EGEA2, suggesting that all participants, regardless of their asthma status at baseline, might have respiratory health benefits by following the AHEI-2010 eating advice. 
Interestingly, our study showed that among never smokers those with a higher AHEI-2010 diet score were more likely to have improved symptoms over time, and this association was not observed among former or current smokers. Different from our finding, some cross-sectional studies reported associations between antioxidant dietary intakes and asthma only in smokers $^{(33,34)}$, hypothesising that smokers who had a higher exposure to oxidants were more likely to benefit from antioxidant dietary intake than never smokers. However, associations between dietary intakes and asthma in both current and former smokers may result from residual confounding by smoking (e.g. smoking intensity and length of time). To minimise potential biases, many asthma studies - RCT in particular - restrict participants to never or non-current smokers ${ }^{(35,36)}$. Besides unhealthy dietary habits, smoking is also associated with other lifestyle factors including sedentary behaviour, and smoking cessation is related to weight gain and overweight ${ }^{(37)}$. Smoking, together with related risk factors for asthma, may attenuate the potential beneficial effect of healthy eating on asthma. Furthermore, smokers appeared to have altered airway inflammation and corticosteroid insensitivity $^{(15)}$, and might represent a particular phenotype of asthma $^{(38)}$. In line with these findings, the results of the present study suggest that smoking is a likely effect modifier in the healthy diet-asthma association. The role of smoking should be carefully addressed in studies on the healthy diet-asthma association and analyses stratified according to smoking are recommended.

As obesity is a likely risk factor for asthma ${ }^{(39,40)}$, it may be a mediator rather than a confounder in the diet-asthma association, in which case adjustment for BMI in the analysis could lead to biased results ${ }^{(11)}$. In the present study, we applied a mediation analysis in the counterfactual framework ${ }^{(21)}$ to study the association between AHEI-2010 and change in asthma symptoms, as well as to quantify the direct effect and indirect effect mediated through BMI. Despite significant total and direct effects, no indirect effect through BMI was observed. Besides, we observed similar results among participants with high or low total energy intake, which do not support the hypothesis that participants with low total energy intake could have more benefits because of a healthier weight. Thus, in this study, BMI was unlikely the key to explain the association between AHEI-2010 and improved asthma symptoms. However, other potential mediators could be involved. For instance, biological markers implicated in specific pathways, such as the response to oxidative/nitrosative stress or inflammation, are likely to advance our understanding regarding the diet-asthma association ${ }^{(41)}$.

We acknowledge a few potential limitations of our study. First, as the AHEI-2010 diet score was associated with COPD $^{(28)}$, the potential overlap between asthma and COPD could contribute to the association between AHEI-2010 and asthma. However, it is unlikely in the present study as similar associations were observed when we excluded participants with $\mathrm{FEV}_{1}$ : FVC $<70 \%$ in the analysis. Second, we acknowledge the possibility of misclassification of the AHEI-2010 assessed by the FFQ. As data for trans-fat were not available in the French food composition table ${ }^{(20)}$, the AHEI-2010 diet score in the EGEA study was calculated without this item, and therefore may not be completely comparable with those in other studies. However, the impact of lacking trans-fat on the investigated association is limited, because, to the best of our knowledge, no evidence has been found on the association between trans-fat and asthma in adults. Third, we acknowledge that potential attrition bias could exist in the present study, as participants lost to follow-up were more likely to be men and had lower AHEI-2010 scores. In addition, reverse causation might still exist in this study. However, the longitudinal design of this study has minimised the possibility, and the change in diet resulting from asthma status is less likely compared with other chronic disease. Finally, similar to any other observational study, even though we controlled for several potential cofounders, the assumption of no unmeasured confounding that is necessary for the validity of our results could be a limitation.

In summary, better diet quality, reflected by a higher AHEI-2010 score, was associated with improved asthma symptoms over time in never smokers, and the association was not mediated through BMI. These findings support the importance of a healthy diet in multi-interventional programmes for asthma and extend the relevance of the AHEI-2010 for lung health.

\section{Acknowledgements}

The authors thank Professor Serge Hercberg who provided us the nutrients database from the SU.VI.MAX survey; Katelle Joly, Anne Forhan and Peggy Drouillet for computation of the nutrients in the EGEA2 survey. The authors also thank all those who participated in setting the present study, the EGEA cooperative group, and they are as follows. Coordination: V. S. (epidemiology, PI since 2013); F. Demenais (genetics); I. Pin (clinical aspects); R. N. (biology); F. Kauffmann (PI 19922012). Respiratory epidemiology: Inserm ex-U 700, Paris: M. Korobaeff (Egea1), F. Neukirch (Egea1); Inserm ex-U 707, Paris: I. Annesi-Maesano (Egea1-2); Inserm ex-U 1018, Villejuif: F. Kauffmann, M. P. Oryszczyn (Egea1-2); Inserm U 1168, Villejuif: N. L. M., R. N., R. V.; Inserm U 1209 Grenoble: V. S. Genetics: Inserm ex-U 393, Paris: J. Feingold; Inserm U 946, Paris: E. Bouzigon, F. Demenais, M. H. Dizier; CNG, Evry: I. Gut (now CNAG, Barcelona, Spain), M. Lathrop (now Univ McGill, Montreal, Canada). Clinical centers: Grenoble: I. Pin, C. P.; Lyon: D. Ecochard (Egea1), F. Gormand, Y. Pacheco; Marseille: D. Charpin (Egea1), D. Vervloet (Egea1-2); Montpellier: J. Bousquet; Paris Cochin: A. Lockhart (Egea1), R. Matran (now in Lille); Paris Necker: E. Paty (Egea1-2), P. Scheinmann (Egea1-2); Paris-Trousseau: A. Grimfeld (Egea1-2), J. Just. Data and quality management: Inserm ex-U155 (Egea1): J. Hochez; Inserm U 1168, Villejuif: N. L. M.; Inserm ex-U780: C. Ravault (Egea1-2); Inserm ex-U794: N. Chateigner (Egea1-2); Grenoble: J. Quentin (Egea1-2).

This research was funded in part by Merck Sharp \& Dohme, the GA2LEN project, Global Allergy and Asthma European Network, and Conseil scientifique AGIR pour les maladies chroniques, National Hospital program of clinical research (PHRC-national). All the funders listed above had no role in the design, analysis or writing of this article.

Z. L., R. N. and R. V.: designed and conducted the study; B. L., N. L. M., C. P., V. S., I. R., R. N. and R. V.: provided essential 
reagents or provided essential materials; Z. L., E. K.-G., O. D., J. G.-A., V. S., C. A. C., R. N. and R. V.: analysed data or performed statistical analysis; Z. L., R. N. and R. V.: wrote the paper and have the primary responsibility for the final content; all the authors have read the manuscript and provided critical revision of the manuscript for important intellectual content and approved the final version.

The authors declare that there are no conflicts of interest.

\section{Supplementary material}

For supplementary material/s referred to in this article, please visit https://doi.org/10.1017/S0007114517000368

\section{References}

1. Devereux G (2006) The increase in the prevalence of asthma and allergy: food for thought. Nat Rev Immunol 6, 869-874.

2. Varraso R (2012) Nutrition and asthma. Curr Allergy Asthma Rep 12, 201-210.

3. Berthon BS \& Wood LG (2015) Nutrition and respiratory health - feature review. Nutrients 7, 1618-1643.

4. Hu FB (2002) Dietary pattern analysis: a new direction in nutritional epidemiology. Curr Opin Lipidol 13, 3-9.

5. Chiuve SE, Fung TT, Rimm EB, et al. (2012) Alternative dietary indices both strongly predict risk of chronic disease. $J$ Nutr 142, 1009-1018.

6. Pekkanen J \& Sunyer J (2008) Problems in using incidence to analyze risk factors in follow-up studies. Eur J Epidemiol 23, 581-584.

7. Pekkanen J, Sunyer J, Anto JM, et al. (2005) Operational definitions of asthma in studies on its aetiology. Eur Respir J 26, 28-35.

8. Sunyer J, Pekkanen J, Garcia-Esteban R, et al. (2007) Asthma score: predictive ability and risk factors. Allergy $\mathbf{6 2}$, 142-148.

9. Boulet L-P (2013) Asthma and obesity. Clin Exp Allergy 43, 8-21.

10. Boggs DA, Rosenberg L, Rodríguez-Bernal CL, et al. (2013) Long-term diet quality is associated with lower obesity risk in young African American women with normal BMI at baseline. J Nutr 143, 1636-1641.

11. Bédard A, Dumas O, Kauffmann F, et al. (2012) Potential confounders in the asthma-diet association: how causal approach could help? Allergy 67, 1461-1463.

12. Richiardi L, Bellocco R \& Zugna D (2013) Mediation analysis in epidemiology: methods, interpretation and bias. Int $J$ Epidemiol 42, 1511-1519.

13. MacNee W (2001) Oxidative stress and lung inflammation in airways disease. Eur J Pharmacol 429, 195-207.

14. Coogan PF, Castro-Webb N, Yu J, et al. (2015) Active and passive smoking and the incidence of asthma in the Black Women's Health Study. Am J Respir Crit Care Med 191, 168-176.

15. Polosa R \& Thomson NC (2013) Smoking and asthma: dangerous liaisons. Eur Respir J 41, 716-726.

16. Kauffmann F, Dizier MH, Pin I, et al. (1997) Epidemiological study of the genetics and environment of asthma, bronchial hyperresponsiveness, and atopy: phenotype issues. $\mathrm{Am} \mathrm{J}$ Respir Crit Care Med 156, S123-S129.

17. Kauffmann F, Dizier MH, Annesi-Maesano I, et al. (1999) EGEA (Epidemiological study on the Genetics and Environment of Asthma, bronchial hyperresponsiveness and atopy) - descriptive characteristics. Clin Exp Allergy 29, Suppl. 4, 17-21.

18. Varraso R, Garcia-Aymerich J, Monier F, et al. (2012) Assessment of dietary patterns in nutritional epidemiology: principal component analysis compared with confirmatory factor analysis. Am J Clin Nutr 96, 1079-1092.

19. Bonifacj C, Gerber M, Scali J, et al. (1997) Comparison of dietary assessment methods in a southern French population: use of weighed records, estimated-diet records and a food-frequency questionnaire. Eur J Clin Nutr $\mathbf{5 1}$, $217-231$

20. Hercberg S, Preziosi P, Briançon S, et al. (1998) A primary prevention trial using nutritional doses of antioxidant vitamins and minerals in cardiovascular diseases and cancers in a general population: the SU.VI.MAX study - design, methods, and participant characteristics. SUpplementation en VItamines et Minéraux AntioXydants. Control Clin Trials 19 , 336-351.

21. Lange T, Vansteelandt S \& Bekaert M (2012) A simple unified approach for estimating natural direct and indirect effects. Am J Epidemiol 176, 190-195.

22. Hafeman DM (2009) 'Proportion explained': a causal interpretation for standard measures of indirect effect? $\mathrm{Am} \mathrm{J}$ Epidemiol 170, 1443-1448.

23. Agence française de sécurité sanitaire des aliments (2009) Etude individuelle Nationale sur les Consommations Alimentaires 2 (INCA 2) 2006-2007. https://www.anses.fr/fr/ system/files/PASER-Ra-INCA2.pdf (accessed July 2016).

24. Global Initiative for Chronic Obstructive Lung Disease (2016) Global strategy for the diagnosis, management, and prevention of chronic obstructive pulmonary disease. http://goldcopd.org/ global-strategy-diagnosis-management-prevention-copd-2016/ (accessed July 2016).

25. Barros R, Moreira A, Fonseca J, et al. (2008) Adherence to the Mediterranean diet and fresh fruit intake are associated with improved asthma control: adherence to Mediterranean diet and asthma control. Allergy $\mathbf{6 3}, 917-923$.

26. Sexton P, Black P, Metcalf $\mathrm{P}$, et al. (2013) Influence of Mediterranean diet on asthma symptoms, lung function, and systemic inflammation: a randomized controlled trial. $J$ Asthma 50, 75-81.

27. Ma J, Strub P, Lv N, et al. (2016) Pilot randomised trial of a healthy eating behavioural intervention in uncontrolled asthma. Eur Respir J 47, 122-132.

28. Varraso R, Chiuve SE, Fung TT, et al. (2015) Alternate Healthy Eating Index 2010 and risk of chronic obstructive pulmonary disease among US women and men: prospective study. BMJ 350, h286.

29. Varraso R \& Camargo CA (2012) Can dietary interventions improve asthma control? Prim Care Respir J 21, 367.

30. Li Z, Rava M, Bédard A, et al. (2017) Cured meat intake is associated with worsening asthma symptoms. Thorax $\mathbf{7 2}$, 206-212.

31. Jiang R, Camargo CA, Varraso R, et al. (2008) Consumption of cured meats and prospective risk of chronic obstructive pulmonary disease in women. Am J Clin Nutr 87, 1002-1008.

32. Varraso R, Jiang R, Barr RG, et al. (2007) Prospective study of cured meats consumption and risk of chronic obstructive pulmonary disease in men. Am J Epidemiol 166 , 1438-1445.

33. Bodner C, Godden D, Brown K, et al. (1999) Antioxidant intake and adult-onset wheeze: a case-control study. Aberdeen WHEASE Study Group. Eur Respir J 13, 22-30.

34. Butland BK, Strachan DP \& Anderson HR (1999) Fresh fruit intake and asthma symptoms in young British adults: confounding or effect modification by smoking? Eur Respir J 13, 744-750. 
35. Price D, Bjermer L, Popov TA, et al. (2014) Integrating evidence for managing asthma in patients who smoke. Allergy Asthma Immunol Res 6, 114-120.

36. Wood LG, Garg ML, Smart JM, et al. (2012) Manipulating antioxidant intake in asthma: a randomized controlled trial. Am J Clin Nutr 96, 534-543.

37. Chiolero A, Faeh D, Paccaud F, et al. (2008) Consequences of smoking for body weight, body fat distribution, and insulin resistance. Am J Clin Nutr 87, 801-809.

38. Bakakos P, Kostikas K \& Loukides S (2016) Smoking asthma phenotype: diagnostic and management challenges. Curr Opin Pulm Med 22, 53-58.
39. Camargo CA, Weiss ST, Zhang S, et al. (1999) Prospective study of body mass index, weight change, and risk of adult-onset asthma in women. Arch Intern Med 159, $2582-2588$.

40. Dixon AE, Pratley RE, Forgione PM, et al. (2011) Effects of obesity and bariatric surgery on airway hyperresponsiveness, asthma control and inflammation. I Allergy Clin Immunol 128, 508-515.e2.

41. Riedl MA \& Nel AE (2008) Importance of oxidative stress in the pathogenesis and treatment of asthma. Curr Opin Allergy Clin Immunol 8, 49-56. 